\title{
Rapid In Situ Immobilization of Enzymes in Metal- Organic Framework Supports under Mild
}

\author{
Conditions Victoria Gascón,$+[a, b]$ Cristina Carucci,$+[b]$ Mayra B.
}

Jiménez,[a] Rosa M. Blanco,[a] Manuel Sánchez-Sánchez, ${ }_{[\text {[a] }}$ Edmond

Magner* $^{*}$ b] The use of a metal-organic framework (MOF) as a support for the in situ immobilization of enzymes was explored. The MOF support, a Basolite F300-like material, was prepared from $\mathrm{FeCl}_{3}$ and the tridentate linker trimesic acid. Immobilization of alcohol dehydrogenase, lipase, and glucose oxidase was performed in situ under mild conditions (aqueous solution, neutral $\mathrm{pH}$, and at room temperature) in a rapid and facile manner with retention of activity for at least 1 week. The catalytic activities of lipase and glucose oxidase were similar to the activities of the free enzymes; with alcohol dehydrogenase, there was a substantial decrease in activity on immobilization that may arise from diffusion limitations. The approach demonstrates that a MOF material, prepared from cheap and commercially available materials, can be successively utilized to prepare stable and catalytically active biocatalysts in a rapid and facile manner. Enzymes are highly selective catalysts that can operate under mild conditions (aqueous solution, room temperature, and moderate $\mathrm{pH}$ ) and can enable shorter synthetic routes that obviate the use of harsh reagents. Significant efforts in using enzymes as catalysts for a wide range of reactions have been made. [1] Advances in biotechnology have enabled the production of enzymes at commercially viable costs with improved catalytic properties such as substrate selectivity, pH optima, and stability.[1] However, the use of enzymes can be restricted by issues such as low stability and difficulties in separation from the reaction mixture and in the reuse of the enzyme. Immobilization can overcome these disadvantages. [1] Many studies have focused on the rational design of a range of materials to provide supports that protect the enzyme with retention of catalytic activity.[2] Supports include inorganic, polymeric, and nano- and porous materials.[3] The use of ordered mesoporous silica materials (OMSMs) modified with a wide range of functional groups has been described.[4] Some of the drawbacks associated with such supports include the need for organic solvents, long or relatively complex preparation procedures, and leaching of the enzyme. Metal-organic framework (MOF) materials are defined by IUPAC as a "coordination network with organic ligands containing potential voids".[5] They have been used for a range of applications in adsorption and gas storage, $[6]$ sensing, $[7]$ catalysis, $[8]$ and drug delivery.[9] The wide range of potential applications of MOFs is based on their topological and compositional versatility.[10] As a consequence, unlike OMSMs, MOF materials can be prepared in a one-step process.[11] In addition, other functional groups can be introduced by changing the organic linker. Usually, MOFs possess a pore diameter in the microporous region ( $<2 \mathrm{~nm}$ ), whereas the typical size of enzymes is approximately $2-20 \mathrm{~nm}$.[12] The development of large-pore MOF materials has enabled the incorporation of small proteins (3-4 nm in diameter). $[12,13]$ However, this approach is not suitable for large enzymes, as the preparation of such MOF materials requires the use of longchain organic linkers that are both difficult and expensive to synthesize.[14] Recently, a MOF with ferritin as the organic linker was described.[13b] The approach required the preparation of protein mutants to generate strong binding regions between the metal and the organic linker. A MOF with catalase embedded into the microcrystals was also reported. ${ }_{[15]}$ However, the activity of the immobilized enzyme was 30 -fold lower than that of the free enzyme,[15] a result of diffusional limitations. Glucose oxidase and horseradish peroxidase were co-immobilized in ZIF-8 and utilized as a colorimetric sensor for glucose; however, details of the activity of the immobilized enzyme relative to that of the free enzyme were not provided.[16] MOFs are generally prepared by using solvothermal processes that involve the use of organic solvents, high temperatures and pressures, or extreme $\mathrm{pH}$ values, conditions that can denature enzymes.[17] Moreover, MOFs are usually not stable in aqueous media. Recently, the preparation of a Basolite F300-like material, based on $\mathrm{Fe}_{3+}$ and the tridentate linker trimesic acid (BTC), under mild aqueous conditions at room temperature was described.[ 18] In this report, we describe the use of this material for the stable immobilization of three large enzymes: NAD+dependent alcohol dehydrogenase (ADH; Saccharomyces cerevisiae), glucose oxidase (GOx; Aspergillus niger), and lipase B (Lip; Candida antartica). Unlike previous in situ immobilization approaches, $[12,15,16]$ this method has the advantage of the rapid generation of immobilized enzymes (in $10 \mathrm{~min}$ ) under mild conditions (in aqueous solution, moderate $\mathrm{pH}$, and at room temperature) with close to $100 \%$ encapsulation of the enzyme from solution (Scheme 1). Using this approach, it is possible, using low costing and commercially available starting materials, to prepare a stable biocatalyst that is ready for operation in less than 1 h. Figure 1. A) XRD patterns of MOF and GOx@MOF prepared from solutions with different 
glucose oxidase concentrations. B) Attenuated total reflection (ATR)-IR spectra of the MOF and E@MOF materials. C) TGA and D) Differential thermogravimetry (DTG) curves of the MOF, lipase, and Lip@MOF. The gray square marks the region attributed to the loss of the enzyme. Scheme 1. Schematic diagram of the preparation of the E@MOF materials. The X-ray diffraction (XRD) pattern of the MOF material (Figure 1a) is similar to that previously reported for Basolite F300[18] with broad peaks arising from the semicrystalline nature of the material. The XRD patterns of GOx@MOF prepared with different enzyme loadings are comparable to the pattern obtained for the MOF material but with changes in the peak intensities at higher enzyme loadings. For Lip@MOF and ADH@MOF, the intensities of the peaks are different even at low enzyme loadings, whereas the positions of the peaks are similar to those of the MOF (Figure 1a and Figure S1 in the Supporting Information). Immobilization of the enzyme on the MOF (postsynthesis) yields very low loadings ( $<3 \%$ at the concentrations examined), which indicates that the enzyme is immobilized in the MOF. In addition, as the MOF support does not contain nitrogen, the presence of the enzyme in the material could be established by the nitrogen content of the $\mathrm{E} @ M O F(E=$ enzyme) (Table S1). The nitrogen adsorption-desorption isotherms of the MOF are indicative of a material with meso- and microporosity ${ }_{[18]}$ (Figure S2, Table S1). The surface area and pore volume of the enzyme-free MOF material are 753 m2g@1 and $0.57 \mathrm{~cm} 3 \mathrm{~g} @ 1$, respectively. The pore volumes and surface areas of the E@MOF materials are significantly lower, which indicates that the E@MOF materials have little or no accessible pores (Figure S2, Table S1). The IR spectrum of the MOF shows weak bands in the region of $n^{\sim}=1300$ to $1700 \mathrm{~cm} @ 1$, whereas in the spectra of the E@MOF samples, the amide bands at $\tilde{n}=1629 \mathrm{~cm} @ 1$ are indicative of the presence of the enzymes in the materials (Fig-ure 1b). Thermogravimetric analysis (TGA) (Figure $1 \mathrm{c}, \mathrm{d}$ ) demonstrates that no loss in mass is detected for the MOF material between approximately 120 and $3208 \mathrm{C}$, whereas mass loss in this temperature range is observed for Lip@MOF, which is indicative of the presence of the enzyme. With ADH@MOF and GOx@MOF, the TGA data are also indicative of the presence of the enzymes (Figure S3 a,b). Scanning electron microscopy (SEM) and transmission electron microscopy (TEM) images (Figures S4 and S5) of the MOF show that the material comprises spherical particles. In the presence of enzymes, the morphology changes and larger, irregular-shaped particles are observed. The particle-size distribution changes as the mean particle size increases from $150 \mathrm{~nm}$ for the MOF to approximately 490 nm for the E@MOF samples (Figure S6). Changes in the morphology and particle-size distribution are again indicative of the inclusion of the enzymes in the support. In the preparation of GOx@MOF and ADH@MOF, all of the available enzyme in solution was immobilized at the concentration ranges examined (Table 1). In contrast, with lipase, the amount of immobilized enzyme decreased as the concentration in solution was increased. The activity of GOx@MOF is 2.4 times higher than that of the free enzyme, an increase that, as previously reported, may arise from interactions between the support and the enzyme.[19] The presence of $\mathrm{Fe}_{3+}$ in solution inhibits the activity of each of the free enzymes. No catalytic activity is observed in the presence of $10 \mathrm{~mm} \mathrm{Fe} 3_{+}$(Table S2), which demonstrates that it is the interactions within the MOF support that affect the catalytic activity, not free $\mathrm{Fe}_{3+}$. In addition, no activity is observed with the MOF on its own for each substrate. With lipase, the activity of the immobilized enzyme is slightly lower than that of the free enzyme. With $A D H$, an enzyme that requires a relatively bulky $N A D_{+}$cofactor, the activity of ADH@MOF is 6\% of the activity of the enzyme in solution, which is indicative of either a reduced rate of diffusion of the cofactor to the enzyme or of interactions between the enzyme and the support that reduce the catalytic activity. Doubling of the NAD+ concentration leads to doubling of the catalytic activity, which indicates that the rate of supply of the cofactor to the enzyme is rate limiting. Although immobilization of enzymes can often lead to diminished catalytic activity, the observed catalytic activity that, for GOx and lipase, is commensurate with the activity in solution is an attractive feature of the E@MOF materials. The activity of the supernatant was examined to ascertain the degree of leaching. After $24 \mathrm{~h}$ incubation in buffer, no activity was detected, indicative of negligible levels of enzyme leaching from the support. Systematic studies on the enzyme loading of Lip@MOF were performed. With GOx and $\mathrm{ADH}$ (Table 1), the specific activity of the immobilized enzyme (Umg@1 of enzyme) decreased as the enzyme loading was increased, whereas with lipase, the specific activity varied with the enzyme loading. At the highest concentrations of enzymes in solution, the immobilized enzymes had lower specific activities, which indicated that some of the enzymes were inaccessible to the substrates. The pH activity profiles of the E@MOF materials are broader than those of the free enzymes (Figure 2a-c), particularly for ADH@MOF, which is indicative of the stabilizing influence of immobilization on the catalytic activity. One of the main advantages of enzyme immobilization is the ability to reuse the biocatalyst. Figure $2 \mathrm{~d}$ shows that the Lip@MOF material retains $87 \%$ of its activity after five cycles (66\% activity after eight cycles, data not shown). GOx@MOF maintains 100\% of it s activity for four cycles, and the activity decreases to 83\% after five cycles. With ADH@MOF, the activity remains stable for the first two cycles and then decreases to $55 \%$ after five cycles. The biocatalysts are stable, and they maintain their 
activities for over 10 days if stored in buffer at $58 \mathrm{C}$ (Figure S7). These results demonstrate that the immobilized enzymes are active for prolonged times over a number of reaction cycles. In conclusion, we described the use of metal-organic framework materials for the in situ immobilization of large enzymes. The method was proven to be rapid and facile, involved the use of cheap, commercially available reagents, and required only mild conditions (aqueous solution, moderate $\mathrm{pH}$, room temperature) to immobilize the enzymes. The approach was successfully demonstrated for three different types of enzymes: alcohol dehydrogenase, lipase, and glucose oxidase. While the precise location and distribution of the enzymes were not discerned, spectroscopic and calorimetric data did demonstrate that the enzymes were immobilized in the materials themselves. The immobilized enzymes were active and stable with retention of activity for at least 1 week. The catalytic activities of the lipase and glucose oxidase were similar to the activities of the free enzymes; in contrast, there was a substantial decrease in the activity of the immobilized alcohol dehydrogenase that likely arose from diffusion limitations of the NAD+ cofactor. The approach described has the potential to be extended to a wide range of enzymes. Acknowledgements Support from the Science Foundation Ireland (12/RC/2275), the Programme for Third Level Institutions, the Irish Research Council (postdoctoral fellowship to V.G. GOIPD/2015/287), and the Spanish Government (MAT-2012-31127) is gratefully acknowledged. This work was also partially financed by the Spanish State Research Agency (Agencia EspaÇola de Investigacijn, $\mathrm{AEI}$ ) and the European Regional Development Fund (Fondo Europeo de Desarrollo Regional, FEDER) through the Project MAT2016-77496-R (AEI/FEDER, UE). We thank Novozyme for the provision of lipase and Dr. Andrea Salis and Dr. Sarah Hudson for critical comments on the manuscript. The authors declare no competing financial interests. A patent application on the preparation of the MOF materials has been filed (V.G., R.M.B., M.S.).

Keywords: biocatalysis · enzymes $\cdot$ immobilization $\cdot$ metal-organic frameworks $\cdot$ supported catalysts

[1] a) L. Cao, Carrier-bound immobilized enzymes: Principles, application and design, 1st ed., Wiley-VCH, Weinheim, 2005; b) U. Hanefeld, L. Cao, E. Magner, Chem. Soc. Rev. 2013, 42, 6211-6212.

[2] L. Cao, Curr. Opin. Chem. Biol. 2005, 9, 217-226.

[3] a) E. Magner, Chem. Soc. Rev. 2013, 42, 6213-6222; b) M. Hartmann, X. Kostrov, Chem. Soc. Rev. 2013, 42, 6277-6289; c) R. A. Sheldon, S. van Pelt, Chem. Soc. Rev. 2013, 42, 6223-6235; d) V. Gascjn, C. M\#rquez-Alvarez, I. D\&az, R. M. Blanco in Non-covalent interactions in the synthesis and design of new compounds (Eds.: A. M. Maharramov, K. T. Mahmudov, M. N. Kopylovich, A. J. L. Pombeiro), Wiley, New York, 2016, pp. $345-$ 360.

[4] a) A. Salis, M. Pisano, M. Monduzzi, V. Solinas, E. Sanjust, J. Mol. Catal. B 2009, 58, 175-180; b) V. Gascjn, C. M\#rquezjlvarez, R. M. Blanco, Appl. Catal. A 2014, 482, 116-126.

[5] a) S. R. Batten, N. R. Champness, X.-M. Chen, J. Garcia-Martinez, S. Kitagawa, L. :hrstrçm, M. O’Keeffe, M. P. Suh, J. Reedijk, Pure Appl. Chem. 2013, 85, 1715-1724; b) L. :hrstrçm, Crystals 2015, 5, 154-162.

[6] D. Liu, H. Wu, S. Wang, Z. Xie, J. Li, W. Lin, Chem. Sci. 2012, 3, $3032-3037$.

[7] L. E. Kreno, K. Leong, O. K. Farha, M. Allendorf, R. P. Van Duyne, J. T. Hupp, Chem. Rev. 2012, 112, $1105-1125$.

[8] S. Horike, M. Dinca, K. Tamaki, J. R. Long, J. Am. Chem. Soc. 2008, 130, 5854-5855.

[9] a) P. Horcajada, T. Chalati, C. Serre, B. Gillet, C. Sebrie, T. Baati, J. F. Eubank, D. Heurtaux, P. Clayette, C. Kreuz, J. S. Chang, Y. K. Hwang, V. Marsaud, P. N. Bories, L. Cynober, S. Gil, G. Ferey, P. Couvreur, R. Gref, Nat. Mater. 2010, 9, 172178; b) J. D. Rocca, D. Liu, W. Lin, Acc. Chem. Res. 2011, 44, 957-968; c) S. Rojas, P. S. Wheatley, E. Quartapelle-

Procopio, B. Gil, B. Marszalek, R. E. Morris, E. Barea, CrystEngComm 2013, 15, 9364-9367.

[10] a) P. Falcaro, R. Ricco, C. M. Doherty, K. Liang, A. J. Hill, M. J. Styles, Chem. Soc. Rev. 2014, 43, 5513-5560; b) R. Ricco, C. Pfeiffer, K. Sumida, C. J. Sumby, P. Falcaro, S. Furukawa, N. R. Champness, C. J. Doonan, CrystEngComm 2016, 18 , 6532-6542c) K. Liang, R. Ricco, C. M. Doherty, M. J. Styles, S. Bell, N. Kirby, S. Mudie, D. Haylock, A. J. Hill, C. J. Doonan, P. Falcaro, Nat. Commun. 2015, 6, 7240.

[11] N. Stock, S. Biswas, Chem. Rev. 2012, 112, 933-969.

[12] J. Mehta, N. Bhardwaj, S. K. Bhardwaj, K.-H. Kim, A. Deep, Coord. Chem. Rev. 2016, 322, 30-40.

[13] a) F. Lyu, Y. Zhang, R. N. Zare, J. Ge, Z. Liu, Nano Lett. 2014, 14, 5761 -

5765; b) P. A. Sontz, J. B. Bailey, S. Ahn, F. A. Tezcan, J. Am. Chem. Soc. 2015, 137, 11598-11601; c) D. S. Raja, W. L. Liu, H. Y. Huang, C. H. Lin, Comments Inorg. Chem. 2015, 35, 331-349.

[14] a) V. Lykourinou, Y. Chen, X. S. Wang, L. Meng, T. Hoang, L. J. Ming, R. L. Musselman, S. Ma, J. Am. Chem. Soc. 2011, 133, 10382-10385; b) H. Deng, S. Grunder, K. E. Cordova, C. Valente, H. Furukawa, M. Hmadeh, F. Gandara, A. C. Whalley, Z. Liu, S. Asahina, H. Kazumori, M. O’Keeffe, O. Terasaki, J. F. Stoddart, O. M. Yaghi, Science 2012, 336, 1018-1023; c)

D. Feng, T. F. Liu, J. Su, M. Bosch, Z. Wei, W. Wan, D. Yuan, Y. P. Chen, X. Wang, K. Wang, X. Lian, Z. Y. Gu, J. Park, X. Zou, H. C. Zhou, Nat. Commun. 2015, 6, 5979.

[15] F. K. Shieh, S. C. Wang, C. I. Yen, C. C. Wu, S. Dutta, L. Y. Chou, J. V. Morabito, P. Hu, M. H. Hsu, K. C. Wu, C. K. Tsung, J. Am. Chem. Soc. 2015, 137, 4276-4279.

[16] X. Wu, J. Ge, C. Yang, M. Hou, Z. Liu, Chem. Commun. 2015, 51, 13408-13411.

[17] P. Horcajada, S. Surble, C. Serre, D. Y. Hong, Y. K. Seo, J. S. Chang, J. M. Greneche, I. Margiolaki, G. Ferey, Chem. Commun. 2007, 2820-2822.

[18] M. Sanchez-Sanchez, I. de Asua, D. Ruano, K. Diaz, Cryst. Growth Des. 2015, 15, 4498-4506.

[19] a) J. Ge, J. Lei, R. N. Zare, Nat. Nanotechnol. 2012, 7, 428-432; b) Z. Li, Y. Zhang, Y. Su, P. Ouyang, J. Ge, Z. Liu, Chem. Commun. 2014, 50, 12465 - 12468; c) E. Castro Miguel, V. Gascon, M. Diaz Garcia, R. Blanco, M. Sanchez- Sanchez, Vol. PCT/ES2016/070397, Spain, 2016, pp. 1-55. 

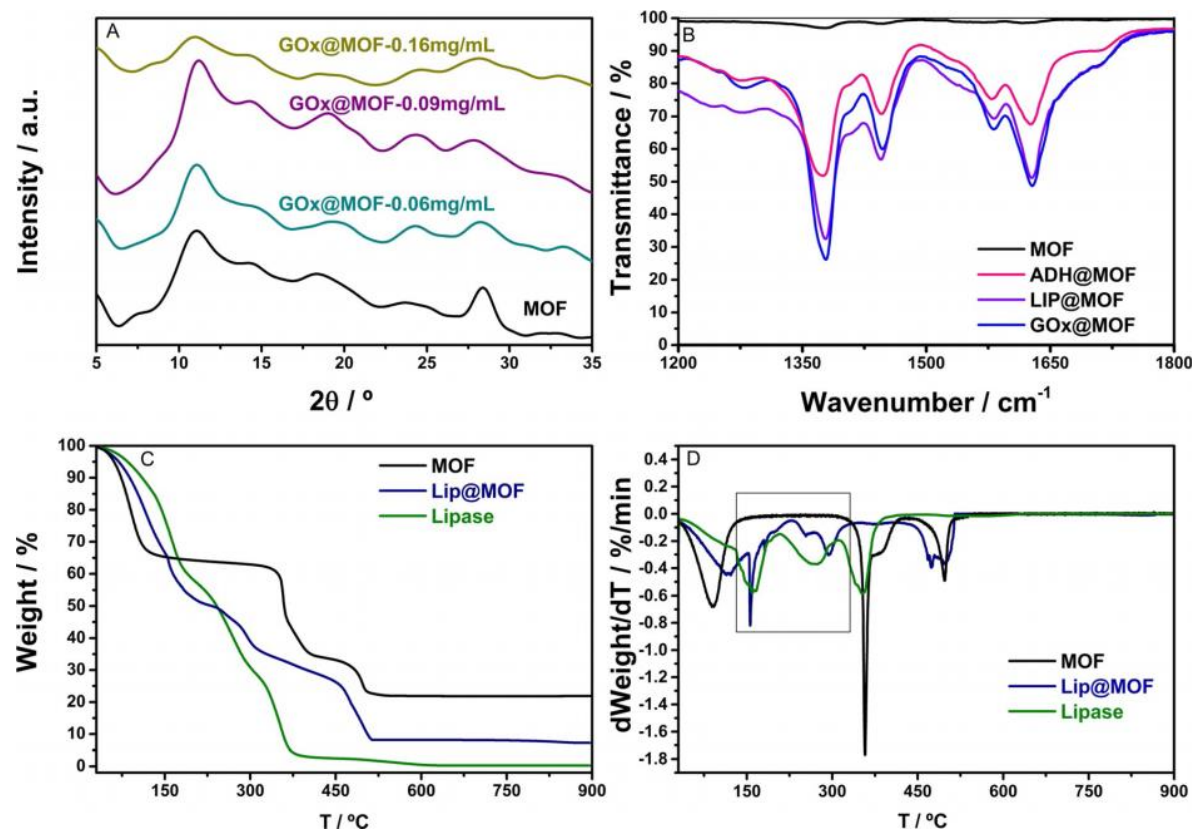

Figure 1. A) XRD patterns of MOF and GOx@MOF prepared from solutions with different glucose oxidase concentrations. B) Attenuated total reflection (ATR)-IR spectra of the MOF and E@MOF materials. C) TGA and D) Differential thermogravimetry (DTG) curves of the MOF, lipase, and Lip@MOF. The gray square marks the region attributed to the loss of the enzyme.

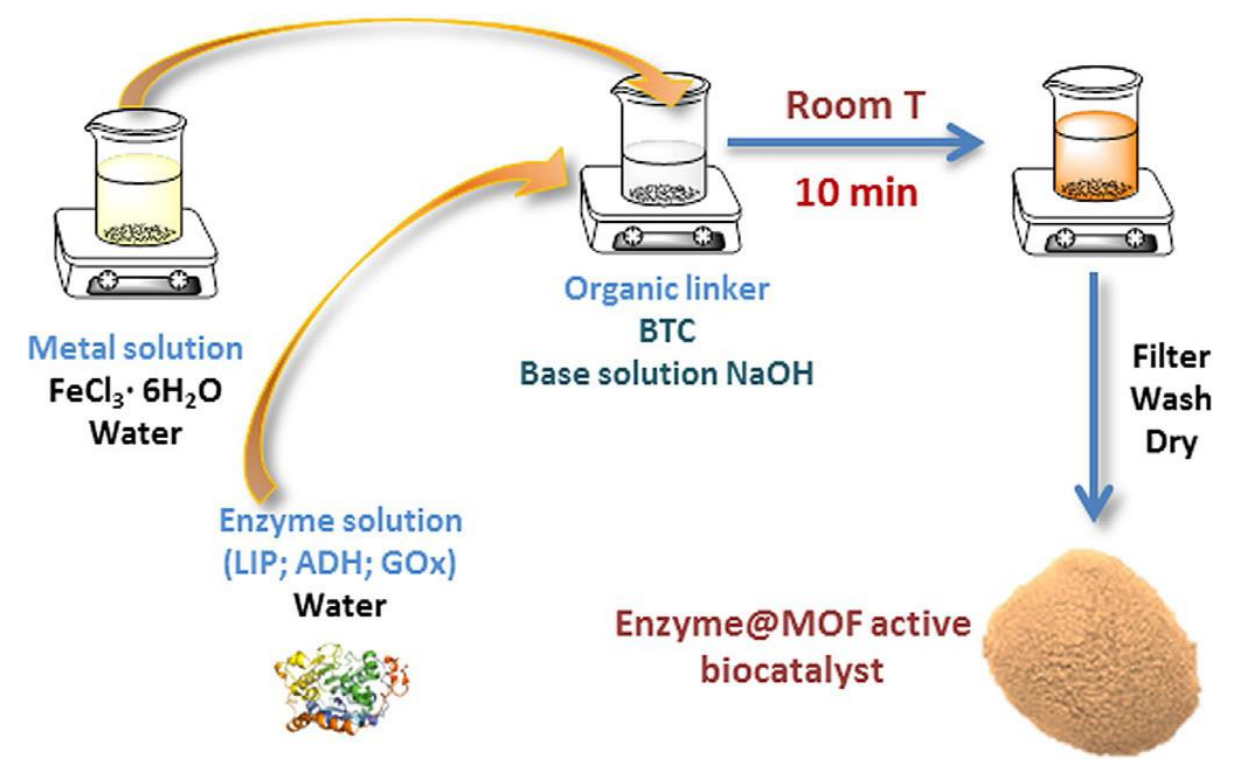

Scheme 1. Schematic diagram of the preparation of the E@MOF materials. 

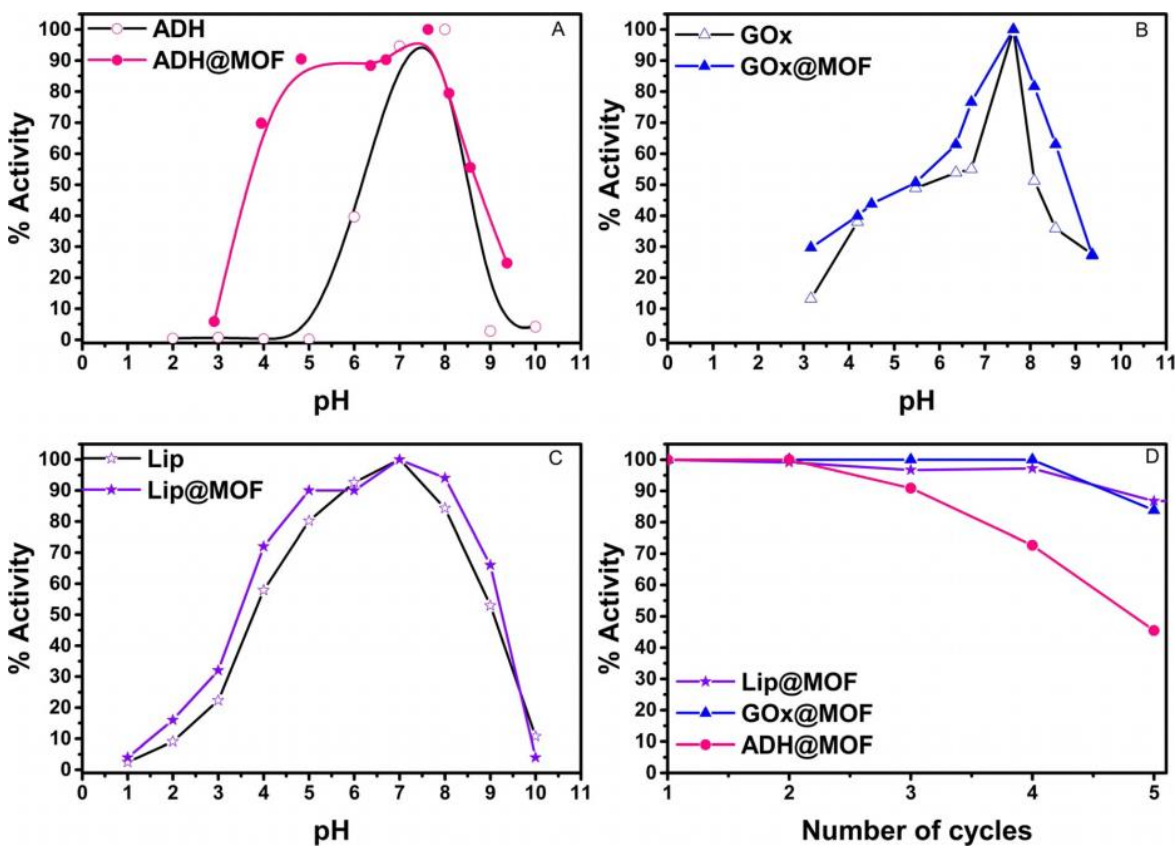

Figure 2. Effect of $\mathrm{pH}$ on the normalized activity of free and immobilized $\mathrm{A}) \mathrm{ADH}, \mathrm{B}) \mathrm{GOx}$, and C) Lip, and D) the activity as a function of the number of reaction cycles.

\begin{tabular}{|c|c|c|c|c|}
\hline $\begin{array}{l}\text { Biocatalyst } \\
\text { MOF }\end{array}$ & $\begin{array}{l}\text { Enzyme } \\
\text { immobized } \\
{[B]}\end{array}$ & $\begin{array}{l}\text { Enzyme } \\
\text { losding } \\
\left.\text { Ing g }{ }^{-1}\right]\end{array}$ & $\begin{array}{l}\text { Activity } y^{p !} \\
{\left[1 g^{-1}\right]}\end{array}$ & $\begin{array}{l}\text { Activity } \\
\left.\text { [Umg }{ }^{-1}\right]\end{array}$ \\
\hline Lip & - & - & - & 2.01 \\
\hline LipD1.5 mg mL & 95 & 165 & 27.55 & 1.67 \\
\hline Lip $97.4 \mathrm{mg} \mathrm{mL}^{-1}$ & 71 & 457 & 90.12 & 1.97 \\
\hline LipD103 $\mathrm{mg} \mathrm{mL}^{-1}$ & 35 & 229 & 33.07 & 1.44 \\
\hline GOx & - & - & - & 1.40 \\
\hline GOND0006 mg mL ${ }^{-1}$ & 100 & 0.87 & 3.0 & 3.40 \\
\hline GOND009 $\mathrm{mg} \mathrm{mL}^{-1}$ & 100 & 108 & 3.6 & 3.28 \\
\hline GOND0.16 $\mathrm{mg} \mathrm{mL}^{-1}$ & 100 & 286 & 4.5 & 1.59 \\
\hline $\mathrm{ADH}$ & - & - & - & 1.58 \\
\hline ADHD0.31 $\mathrm{mg} \mathrm{mL}^{-1}$ & 100 & 10.1 & 0.59 & 0.058 \\
\hline ADHD $1.8 \mathrm{mg} \mathrm{mL}^{-1}$ & 100 & 68.4 & 0.62 & 0.091 \\
\hline $\mathrm{ADHD} 24 \mathrm{mg} \mathrm{mL}^{-1}$ & 100 & 996 & 0.51 & 0.005 \\
\hline
\end{tabular}

